\title{
The direct measurement of ATP and adenine nucleotide pool turnover in microorganisms: a new method for environmental assessment of metabolism, energy flux and phosphorus dynamics*
}

\author{
Peter Bossard ${ }^{1}$ and David M. Karl \\ Department of Oceanography, University of Hawaii, Honolulu, HI 96822, \\ USA
}

${ }^{1}$ Current address: Lake Research Laboratory, EAWAG/ETH, $\mathrm{CH}-6047$

Kastanienbaum, Switzerland

\begin{abstract}
A method has been devised which enables the direct measurement of ATP and adenine nucleotude pool turnover. The method is based upon the incorporation of ${ }^{32} \mathrm{PO}_{4}$ into the $\alpha-\beta-, \gamma-\mathrm{P}$ positions of ATP. ${ }^{32} \mathrm{PO}_{4}$ uptake time course expenments were conducted in seawater and freshwater samples. Determinations of the ATP concentration and of the specific activities of the $\alpha-, \beta$ - and $\gamma$-positioned ${ }^{32} \mathrm{P}$ in ATP at sequentral time points enables the calculation of: (1) the pool size of total biologically available $\mathbf{P}$ in water samples; (2) the rate of biochemucal energy flux; and (3) the mean microbial community specific growth rate. This method is relatively simple, straightforward and extremely sensitive. It has, therefore, the advantage that it can be employed in environments where dissolved $\mathbf{P}$ levels are too low to obtain reliable $\mathbf{P}$ flux estimates using existung techniques.
\end{abstract}

\section{Introduction}

Phosphorus $(\mathrm{P})$ is an essential macro nutrient for all micro-organisms and in many natural environments $P$ has actually been identified as the growth rate-limiting nutrient (Rhee, 1973, Perry, 1976). The principle pathways and mechanisms of $P$ cycling in aquatic environments have been discussed previously (Medveczky and Rosenberg, 1971; Lehman, 1980; Scavia, 1980; Nalewajko and Lean, 1981). Despite the fact that P occurs almost exclusively in a single valence state (i.e., +5 , as $\mathrm{PO}_{4}^{-3}$ ) whether associated with organic or inorganic derivatives, the $\mathrm{P}$ cycle in aquatic ecosystems is extremely complex (Watt and Hayes, 1963; Lean, 1973; Halmann and Stiller, 1974; Cosgrove, 1977; Berman and Skyring, 1979; Fenchel and Blackburn, 1979; Lean and White, 1983), especially with regard to the tendency to form chemically stable organic P-esters [e.g., nucleotides, nucleic acids, phospholipids, sugar phosphates; cf. Miyachi and Tamiya (1961) and Kanai and Simonis (1968)] and relatively insoluble metallic P-salts (e.g., calcium, phosphate, ferric phosphate).

Most investigations of the $\mathrm{P}$ cycle in natural ecosystems have involved the use of ${ }^{32} \mathrm{P}$ and ${ }^{33} \mathrm{P}$ radiotracers to estimate $P$ mass flux through the various idealized extra-cellular and intra-cellular compartments. A major limitation of this approach is the inability to measure the specific radioactivity (i.e., radioactivity per unit mass) of each separate $\mathbf{P}$ containing pool, which must be known in order to calculate mass fluxes of $P$. This is especially critical for studies of microbiological $P$ uptake, since the mere determination of gross uptake into particles is not necessarily representative of $P$ fluxes, due to com-

\footnotetext{
*This paper is the result of a study made at the Group for Aquatic Primary Productivity (GAP). Second International Workshop held at the National Oceanographic Instirute, Haifa. Israel in April-May 1984.
} 
plications resulting from uncertainties in the extent of isotope dilution (especially in environments exhibiting low $\mathrm{PO}_{4}$ concentrations), rapid $\mathrm{P}$ cycling, abiotic ${ }^{32} \mathrm{P}$ association (adsorption) and the diversity of potentially utilizable inorganic and organic $\mathrm{P}$ pools (Taft et al., 1977; Tarapchak, 1981; Lean and White, 1983).

We believe that many of these current limitations and shortcomings can be alleviated by direct measurements of the time-dependent changes and absolute magnitude of the specific radioactivities of the $\gamma$ - and $\alpha$-positioned P of total microbial community ATP pools (Karl and Bossard, 1985a) after short-term incubation in ${ }^{32} \mathrm{PO}_{4}$. Each molecule of ATP contains three phosphate groups in a linear arrangement designated the $\alpha, \beta$ and $\gamma$ (terminal) positions, respectively. There is strong evidence that ATP is the immediate precursor for many low- and high-molecular-weight intracellular P-containing compounds, which is confirmed in the case of sugar-P, phospholipids and nucleic acids. Consequently, data on the specific activity of $\alpha / \gamma$-positioned P of ATP may provide useful information required to calculate accurate $P$ mass fluxes. Apart from its role as an intermediate pool for intracellular P-mass transfer, ATP is also important for biochemical energy transfer. In as much as ATP is involved directly or indirectly (NAD, NADP, FAD-regeneration, non-adenine NTPs) with all chemical energy transfers within a cell (Atkinson, 1977), ATP turnover is representative of biochemical energy flux. Turnover in the present context refers to the utilization of the $\gamma$ (terminal)-phosphate group of ATP and the subsequent regeneration of ATP. ATP is believed to turn over very quickly (Chapman and Atkinson, 1977). Therefore, if a radiotracer $\left({ }^{32} \mathrm{PO}_{4}\right)$ is added to the extracellular P pool, the specific activity of $\gamma$-P in ATP should reach isotopic equilibrium with the extracellular available $P$ relatively quickly when compared to other intracellular $P$ pools. When isotopic equilibrium is achieved, the value of the specific activity of the $\gamma$-P of ATP should enable an independent calculation of the pool size of extracellular $P$ available to the microbial community. Finally, since adenine nucleotides also serve as important biosynthetic precursors for nucleic acids and histidine, and since the $\alpha$ positioned P of ATP becomes labeled only as ATP is removed and re-synthesized (Chapman and Atkinson, 1977), direct measurement of the turnover of $\alpha-P$ should yield quantitative information on microbial growth rate.

It is the aim of this investigation to show potential applications of the methods devised by Karl and Bossard (1985a), which enables one to determine the specific radioactivities of the $\alpha$ - and $\gamma$-positioned phosphate groups in ATP. Although these quantitative assessments can be applied to any population of micro-organisms, including monocultures, mixed cultures or diverse environmental samples, we will restrict our present discussion to the initial results obtained during field studies with marine and freshwater samples containing natural mixed plankton populations and to a discussion of the ecological interpretations of these data.

\section{Materials and methods}

Theory and outline of the method used for the determination of the specific activities of $\alpha-P$ and $\gamma-P$ in ATP (each molecule of ATP contains three phosphate groups in a linear arrangement designated the $\alpha-, \beta$ - and $\gamma$-P positions, respectively)

For the determination of the specific activities of the individual phosphate groups (i.e., $\mathrm{nCi}^{32} \mathrm{P} \mathrm{pmol}-1$ total $\mathrm{P}$ ), chromatographically purified ATP is subjected to specific en- 
zymatic hydrolysis designed to release either the $\gamma$ (ATPase reaction) or $(\gamma+\beta)$ phosphate groups (apyrase reaction). $\mathrm{The}^{32} \mathrm{PO}_{4}$ released during the enzymatic hydrolysis procedure is separated from the parent adenine nucleotide moiety by activated charcoal treatment and is radioassayed. From time-course measurements, the rates of $\alpha-\mathrm{P}$ and $\gamma-\mathrm{P}$ incorporation can be measured directly and the ATP and adenine nucleotide (AN) turnover rates calculated. A complete description of the analytical methods is presented elsewhere (Karl and Bossard, 1985a).

\section{Sample collection and ${ }^{32} \mathrm{PO}_{4}$ labeling}

Field samples were collected from a freshwater pond on the University of Hawaii campus (Krauss Pond), an outdoor marine algal mass culture facility located in Honolulu (Algal Raceway), and at an offshore hydrostation located approximately $6 \mathrm{~km} \mathrm{NE}$ of Kaneohe Bay, Hawaii, at $21^{\circ} 29.8^{\prime} \mathrm{N} ; 157^{\circ} 45.5^{\prime} \mathrm{W}$ [Ocean Station; cf. Laws et al. (1984)]. The samples were collected manually in acid-washed polycarbonate bottles and were prefiltered through a $95 \mu \mathrm{m} \mathrm{Nitex}{ }^{\circledR}$ screen prior to the start of the experiment in order to remove larger organisms. The sample collected from Ocean Station was maintained overnight in a 20-1 acid-washed glass bottle with a magnetic stirrer at approximate in situ temperature $\left(\sim 24^{\circ} \mathrm{C}\right)$ prior to the start of the experiment. The incubations began with the addition of ${ }^{32} \mathrm{PO}_{4}$ (carrier free; New England Nuclear Corp.) to a final activity of between 0.1 and $2 \mu \mathrm{Ci} \mathrm{ml}^{-1}$ depending upon the desired sensitivity and anticipated ambient total dissolved phosphorus (TDP) concentrations. In selected experiments [2- $\left.{ }^{3} \mathrm{H}\right]$-adenine ( $15 \mathrm{Ci} \mathrm{mmol}^{-1}$; New England Nuclear Corp.) was added, together with ${ }^{32} \mathrm{PO}_{4}$, to a final activity of $0.1-0.2 \mu \mathrm{Ci} \mathrm{ml}{ }^{-1}$. All incubations were performed under simulated in situ conditions in the laboratory. After selected time periods, sub-samples were removed for ATP extraction and purification (see below) and during selected experiments, for gross uptake of ${ }^{32} \mathrm{P}$ and ${ }^{3} \mathrm{H}$ and for incorporation of ${ }^{32} \mathrm{P}$ and ${ }^{3} \mathrm{H}$ into RNA and DNA (Karl, 1981).

\section{ATP extraction and purification}

The removed sub-samples were extracted for total ATP by either glass fiber filter (GF/F, Whatman) concentration of particulate matter and subsequent boiling phosphate buffer (pH 7.4, 60 mM) extraction ('slow extraction') or by acidification of the total water sample to a final concentration of $1 \mathrm{M} \mathrm{H}_{3} \mathrm{PO}_{4}$ ('fast extraction'). The aqueous extracts were concentrated in vacuo and assayed for total ATP as described previously (Karl et al., 1981). The acid extracts were concentrated and de-salted using the activated charcoal adsorption procedure of Hodson et al . (1976). ATP purification was achieved by a twostep one-dimensional separation using polyethyleneimine (PEI) t.l.c. (Karl and Bossard, 1985a).

\section{Rates of RNA synthesis}

Rates of RNA and DNA synthesis were measured in selected experiments according to Karl and Bossard (1985b) from $\left[{ }^{3} \mathrm{H}\right]$ adenine incorporation, and according to Karl and Bossard (1985a) from ${ }^{32} \mathrm{PO}_{4}$ incorporation into nucleic acids, taking into account the specific activity of the $\alpha-\mathrm{P}$ of the ATP precursor pool.

Soluble reactive phosphorus

Soluble reactive phosphorus [SRP, also referred to as orthophosphate; (Rigler, 1973)] 
was analyzed by the molybdenum blue method (Vogler, 1965). The detection level was $0.05 \mu \mathrm{M}$, and the standard deviation for concentrations between 0.1 and $0.2 \mu \mathrm{M}$ was $0.03 \mu \mathrm{M}$.

\section{Ocean Station experiment}

The Ocean Station experiment was the most comprehensive experiment of the field investigations presented here. Other experiments (Krauss Pond, Algal Raceway) contained modified portions of the procedures described below.

\section{Rapid ${ }^{32} \mathrm{PO}_{4}$ incorporation}

This portion of the experiment was devised to follow the kinetics of ${ }^{32} \mathrm{P}$ incorporation into the $\beta$ - and $\gamma$-positioned phosphate groups of ATP. Ten separate 200 -ml sub-samples were transferred from the 20-1 reservoir into polycarbonate bottles and inoculated with ${ }^{32} \mathrm{PO}_{4}$, as described above. After incubation periods ranging from 0.2 to $16 \mathrm{~min}, 15 \mathrm{ml}$ of concentrated $\mathrm{H}_{3} \mathrm{PO}_{4}(14.7 \mathrm{M})$ was injected into each sub-sample, which resulted in instantaneous cell death and ATP release. The cell extracts were stored at $-20^{\circ} \mathrm{C}$ until processed for ATP and $\mathrm{AT}^{32} \mathrm{P}$ within 2 days. We determined ATP to be stable under these conditions; however, it should be emphasized that even if losses occurred this would not affect the resultant specific radioactivities (i.e., activity per unit mass), which are independent of total concentration.

Dual labeled ${ }^{3} \mathrm{H} /{ }^{32} \mathrm{P}$ experiment. The water remaining in the $20-1$ glass bottle was mixed with ${ }^{32} \mathrm{PO}_{4}$ and $\left[{ }^{3} \mathrm{H}\right]$ adenine and after incubation periods ranging from 5 to $380 \mathrm{~min}$, 750-ml sub-samples were withdrawn and processed as follows: (1) $200 \mathrm{ml}$ was transferred to a polycarbonate bottle, mixed with $15 \mathrm{ml}$ of concentrated $\mathrm{H}_{3} \mathrm{PO}_{4}$ ("fast ATP extraction'); (2) the particulate matter from $100 \mathrm{ml}$ was concentrated on to a $\mathrm{GF} / \mathrm{F}$ filter, rinsed with $1 \mathrm{ml}$ of filtered sea water, and assayed for net uptake of ${ }^{3} \mathrm{H}$ and ${ }^{32} \mathrm{P}$ by liquid scintillation counting; (3) $200 \mathrm{ml}$ was filtered (GF/F) and extracted in boiling $\mathrm{PO}_{4}$ buffer ('slow ATP extraction'); and (4) $200 \mathrm{ml}$ was filtered (GF/F) and the filter stored frozen until processed for ${ }^{32} \mathrm{P}$ and ${ }^{3} \mathrm{H}$ incorporation into RNA and DNA.

\section{Results and Discussion}

\section{Characteristics of ${ }^{32} P$ uptake}

Uptake kinetics and intracellular distribution of ${ }^{32} P$. In the Ocean Station experiment, net uptake of ${ }^{32} \mathrm{PO}_{4}$ into particulate matter $(>0.4 \mu \mathrm{m})$ was linear with time during the first $2 \mathrm{~h}$ and was subsequently enhanced during the next $4 \mathrm{~h}$ of observation (Figure $1 \mathrm{~A}$ ). This is in accordance with the observed increase in ATP concentration, assumed here to be an indicator of total microbial biomass. During a 6-h incubation period the microbial community (and other particulates) removed only a small portion $(<15 \%)$ of the total ${ }^{32} \mathrm{PO}_{4}$ added. SRP concentrations varied during the experiment between 0.10 and 0.16 $\mu \mathrm{M}$. Assuming a mean absolute error of $\pm 0.03 \mu \mathrm{M}$ in SRP analysis leads us to the conclusion that the SRP concentration was quite stable during the incubation period. The specific activity of the SRP pool at an average concentration of $0.13 \mu \mathrm{M}$ was equivalent to $1.3 \mathrm{mCi}^{32} \mathrm{P} \mu \mathrm{M}^{-1}$ phosphate.

Figure $1 \mathrm{~B}$ shows the amount of ${ }^{32} \mathrm{P}$ incorporated into RNA, DNA and ATP as a frac- 

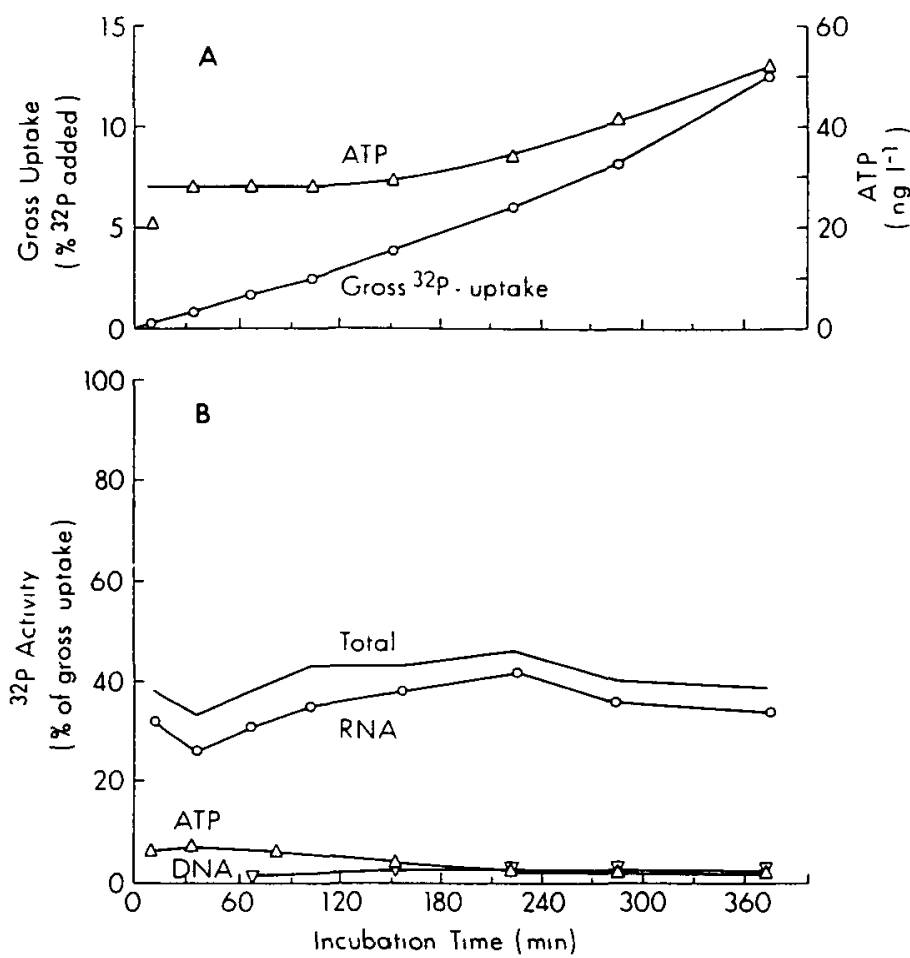

Fig. 1. Kinetics of ${ }^{32} \mathrm{P}$-uptake into different intracellular fractions at Ocean Station (off Kaneohe Bay).(A) ${ }^{32} \mathrm{P}$ activity in particulate matter $(>0.4 \mu \mathrm{m})$ as a fraction of ${ }^{32} \mathrm{PO}_{4}$ added ('gross uptake') and ATP concentration in $n g \mathrm{I}^{-1}$ versus incubation time in min. (B) ${ }^{32} \mathrm{P}$ activity in RNA, DNA and ATP as a fraction of the ${ }^{32} \mathrm{P}$ activity in particulate matter versus incubation time in $\mathrm{min}$. Total = sum of RNA, DNA and ATP radioactivities.

tion of total uptake. At least two consistent and somewhat unexpected features were observed, including: (1) the sum of $\left.{ }^{32} \mathrm{P}\right] \mathrm{RNA},\left[{ }^{32} \mathrm{P}\right] \mathrm{DNA}$ and $\mathrm{AT}^{32} \mathrm{P}$ accounts for slightly less than $50 \%$ of the gross ${ }^{32} \mathrm{P}$ uptake. These data suggest that other pools, such as intracellular orthophosphate, polyphosphate, lipid-P or sugar-P, appear to consume as much $\mathrm{P}$ as the sum of the nucleotides and nucleic acids, although we cannot rule out the possibility of time-dependent adsorption onto non-living particulate matter; and (2) ${ }^{32} \mathrm{P}$ incorporated into RNA represents a relatively constant fraction of gross uptake independent of incubation period. Since only the $\alpha$-positioned P of NTPs is incorporated into RNA, these results suggest that the cellular NTP pools turn over very quickly (i.e., on time scales of $\mathrm{min}$ ) to enable the observed ${ }^{32} \mathrm{P}$-incorporation into RNA.

A freshwater sample collected from Krauss Pond exhibited very different ${ }^{32} \mathrm{P}$ gross uptake kinetics (Figure 2A). These results indicated that greater than $95 \%$ of the ${ }^{32} \mathrm{PO}_{4}$ added was taken up within a few minutes, suggesting rapid $\mathrm{PO}_{4}$ turnover. Microbial biomass (as determined by ATP concentration) was approximately three orders of magnitude greater than in the Ocean Station experiment, an observation which is consistent with the rapid assimilation of the added ${ }^{32} \mathrm{PO}_{4}$. The SRP concentration measured at the beginning of the incubation was $0.8 \mu \mathrm{M}$, with an extrapolated specific activity of $1.28 \mathrm{mCi}^{32} \mathrm{P} \mu \mathrm{M}^{-1}$ phosphate. The incorporation of ${ }^{32} \mathrm{PO}_{4}$ into microbial RNA, DNA 

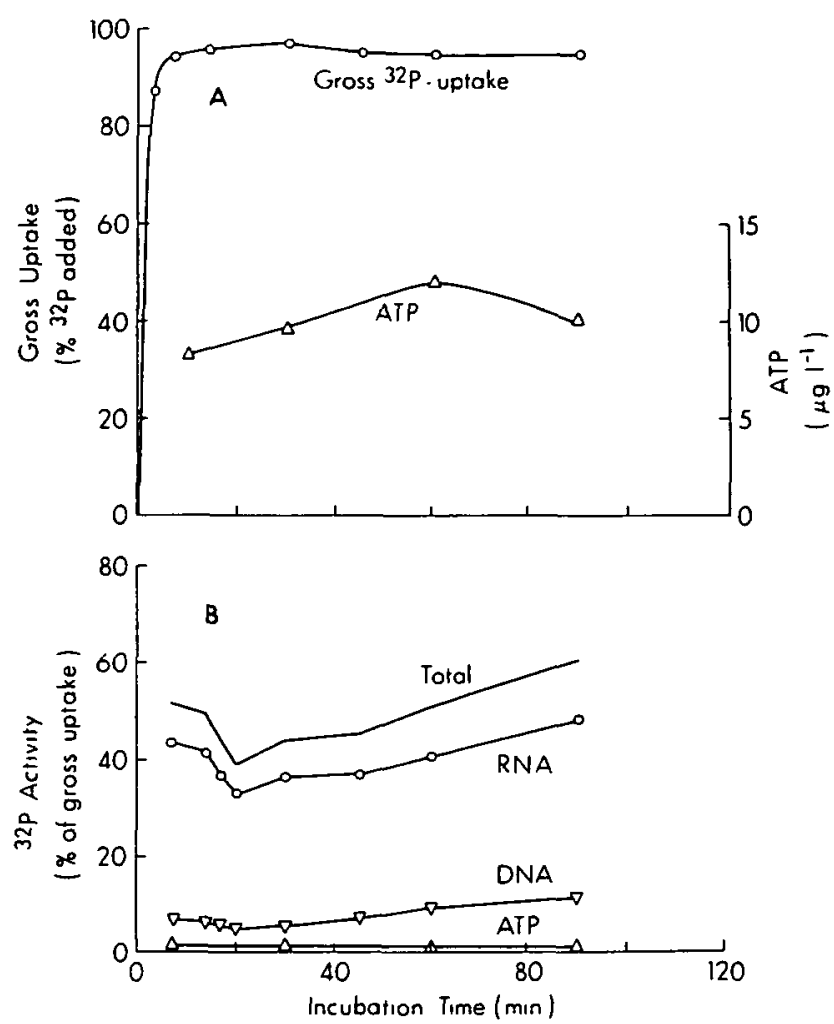

Fig. 2. Kinetics of ${ }^{32} \mathrm{P}$-uptake into different intracellular fractions in Krauss Pond. (A) ${ }^{32} \mathrm{P}$ activity in particulate matter $(>0.4 \mu \mathrm{m})$ as a fraction of ${ }^{32} \mathrm{PO}_{4}$ added ('gross uptake') and ATP concentration in $\mu \mathrm{g}^{-1}$ versus incubation time in min. (B) ${ }^{32} \mathrm{P}$ activity in RNA, DNA and ATP as a fraction of the ${ }^{32} \mathrm{P}$ activity in particulate matter versus incubation time in $\min$. Total $=$ sum of RNA, DNA and ATP radioactivities.

and ATP, when expressed as a percentage of gross uptake (Figure 2B), was similar to that observed in the Ocean Station experiment.

\section{Kinetics of ${ }^{32} P$-incorporation into ATP}

Four different sets of environmental samples were selected to illustrate ${ }^{32} \mathrm{P}$-incorporation kinetics into ATP. The oligotrophic Ocean Station, with slow ${ }^{32} \mathrm{P}$ gross uptake (Figure 1A), incorporated ${ }^{32} \mathrm{P}$ into the $\beta-\mathrm{P}$ and $\gamma-\mathrm{P}$ positions of ATP immediately after ${ }^{32} \mathrm{PO}_{4}$ addition, while the $\alpha-P$ remained unlabeled for the first $15 \mathrm{~min}$.

The $\alpha-, \beta-$, and $\gamma-$ P positions of ATP attained equal specific radioactivities before isotopic equilibrium with the precursor pool was reached (Figure 3). These data also indicate that the $\beta-\mathrm{P}$ and $\gamma-\mathrm{P}$ are labeled at the same rate (i.e., have equivalent turnover times), which supports the principle assumption underlying the ATPase method (see Discussion presented in Karl and Bossard, 1985a). The eutrophic Algal Raceway samples exhibited similar incorporation kinetics (Figure 4). The initial time lag between $\gamma$ - and $\alpha^{-32} \mathrm{P}$ labeling kinetics is clearly seen. In the light (Figure 4A) specific activities of $\alpha$ and $\gamma$-P are higher than in the dark (Figure $4 B$ ) at equal incubation times.

The kinetics of ATP labeling of samples collected from Krauss Pond were quite dif- 


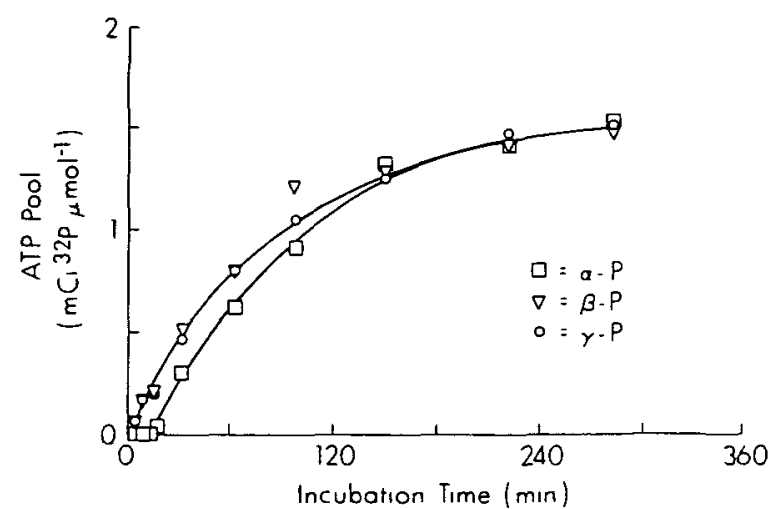

Fig. 3. Kinetıcs of ${ }^{32} \mathrm{P}$-ıncorporatıon into ATP at Ocean Statıon. Specific actıvities of $\alpha-\beta$ - and $\gamma-\mathrm{P}$ in $\mathrm{mCi}$ ${ }^{32} \mathrm{P} \mu \mathrm{mol}^{-1}$ ATP versus incubation time in min.
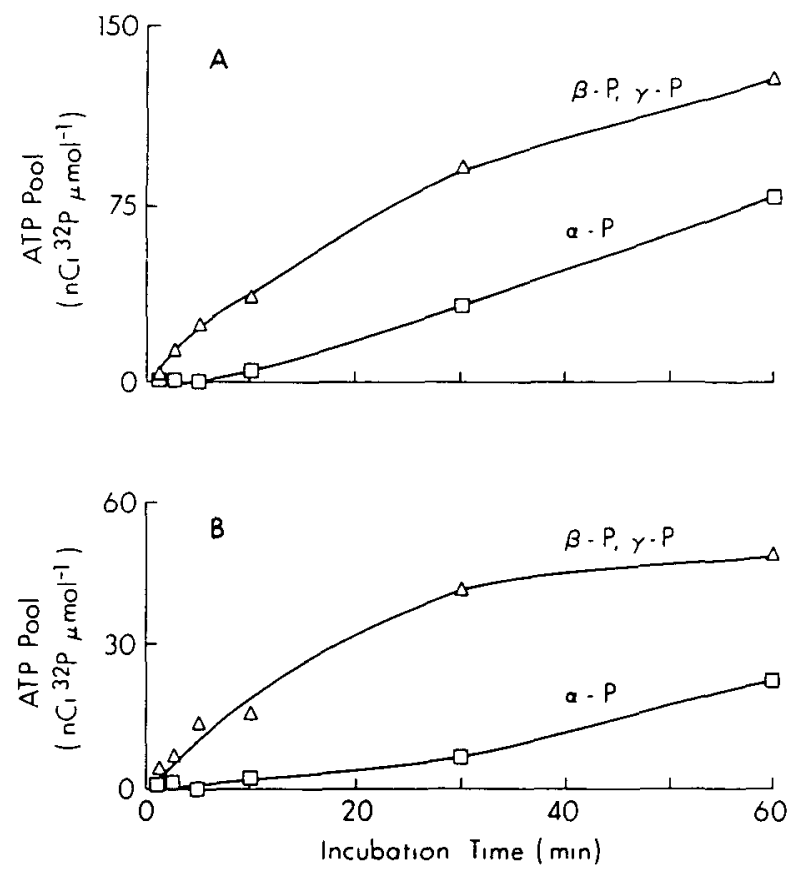

Fig. 4. Kinetics of ${ }^{32} \mathrm{P}$-1ncorporation into ATP in Algal Raceway. Specific activitues of $\alpha^{-}, \beta$ - and $\gamma-\mathrm{P}$ in $\mathrm{nC}_{1}$ ${ }^{32} \mathrm{P} \mu \mathrm{mol}^{-1}$ ATP versus incubation time in min. calculated from hydrolysis with apyrase $(\gamma-\mathrm{P}$ assumed to be $\beta$-P). (A) Light incubation; (B) Dark incubation.

ferent (Figure 5). The ATP pool reached maximum specific activity before the first samples were taken and decreased with extended incubation period. This is consistent with the observation cited previously (Figure $2 \mathrm{~A}$ ) regarding the rapid uptake and turnover of the added ${ }^{32} \mathrm{PO}_{4}$ (i.e., $>95 \%$ taken up in first $10 \mathrm{~min}$ of the incubation period). While the specific radioactivity of the $\beta-\mathrm{P}$ and $\gamma-\mathrm{P}$ decreased beyond $10 \mathrm{~min}$, the $\alpha-\mathrm{P}$ specific activity continued to rise for the first $30 \mathrm{~min}$ of the incubation period. These results once 


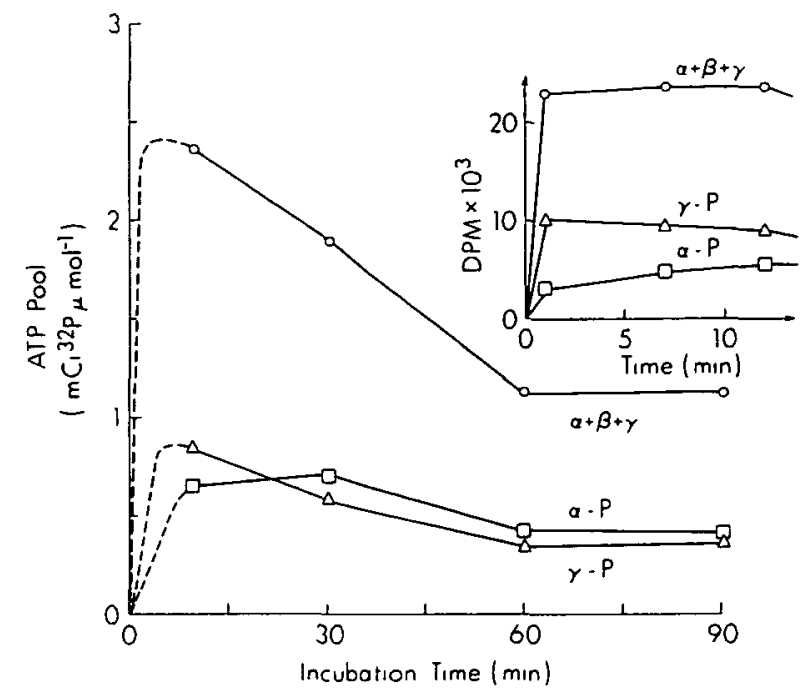

Fig. 5. Kinetics of ${ }^{32} \mathrm{P}$-incorporation into ATP in Krauss Pond. Specific activities of total ATP $(\alpha+\beta+$ $\gamma-\mathrm{P}$ ) and of $\alpha$ - and $\gamma-\mathrm{P}$ in $\mathrm{mCl}_{\mu} \mu \mathrm{mol}^{-1}$ ATP versus incubation tıme in min. Inset: Similar experiment with shorter incubation time and sampling intervals.

again support our initial hypothesis regarding the differential metabolic function of the $\gamma$-P and $\beta$-P versus the $\alpha$-P of ATP.

Calculation of $A T P(\gamma-P)$ and $A N(\alpha-P)$ tumover times

The role of the adenine nucleotides (AMP, ADP, ATP) as energy transducers is well documented. The adenine nucleotide moiety is not consumed in this process and ADP and ATP are re-generated from AMP and ADP, respectively, by catabolic reactions. Equilibrium among these species is maintained by the activity of the enzyme adenylate kinase ( $2 \mathrm{ADP} \rightleftharpoons \mathrm{AMP}+\mathrm{ATP}$ ) poised by the cellular adenylate energy charge (Atkinson, 1977). During this process only the $\beta$ - and $\gamma$-positioned P groups of ATP would be expected to become labeled, and at the same rate. The adenine nucleotide moiety is also a precursor for macro-molecular biosynthesis, which in the case of nucleic acid synthesis results in a net removal of ATP as AMP. Consequently, there is always a net demand for $\mathrm{PO}_{4}$ to make up for the $\mathrm{P}$ depletion in the ATP pool. During this re-supply process the $\alpha$-position of ATP also becomes labeled. The time required to reach isotopic equilibrium in $\alpha$ - and $\gamma$-P with their immediate presursor pools (i.e., extracellular or intracellular $\mathrm{PO}_{4}$ ) is independent of the ratio of ${ }^{32} \mathrm{P} /{ }^{31} \mathrm{P}$, as long as this ratio is constant over the observation period (Karl and Bossard, 1985a), which means that extracellular $\mathrm{PO}_{4}$ is either directly incorporated into $\alpha$ - or $\gamma$-P-ATP or via a hypothetical intermediate intracellular $\mathrm{PO}_{4}$-precursor pool, whose isotopic equilibrium must be achieved much faster than the one in ATP.

Turnover time can be calculated if the specific activities of $\alpha-\mathrm{P}$ and $\gamma-\mathrm{P}$ are monitored as a function of incubation time (see Figure 3, Ocean Station). If we assume that the change in the $\alpha-\mathrm{P}$ or $\gamma$-P specific activity (SA; $\mathrm{nCi} \mathrm{pmol}^{-1}$ ) of ATP is an exponential function of incubation time $(t)$, and that the initial SA (at $\left.t_{0}\right)=0$ and the maximum SA 
(at isotopic equilibrium) $=1.00$, then the decimal $(0-1.00)$ equivalent of the SA of the $\alpha$ - or $\gamma$-P of ATP at any time $\left(\mathrm{SA}_{t}\right)$ is given by the equation:

$$
\mathrm{SA} t=1-(2-M)
$$

where $N$ is the number of turnover cycles (i.e., dimensionless number) observed during the incubation period. ATP pool turnover time (from the $\gamma$-positioned P SA data) and AN pool turnover time (from the $\alpha$-positioned P SA data) can be calculated from the expression:

$$
T=t / N
$$

where $T$ is the turnover time in $\mathrm{s}$, $\min$ or $\mathrm{h}$. This equation holds for incubation periods $(t)$ less than or equal to $5 \mathrm{~N}$, at which point the SA becomes analytically indistinguishable from that of the precursor pool (i.e., a relative $S A=1.00 \pm 0.05$ ). At Ocean Station isotopic equilibrium is reached after approximately $240 \mathrm{~min}$ for both $\alpha$ - and $\gamma$-P of ATP. Both pools are therefore turning over approximately once every $50 \mathrm{~min}$.

Krauss Pond (Figure 5) is a good example of an environment where neither the ATP nor AN turnover times can be determined properly because the turnover time of the extracellular ${ }^{32} \mathrm{P}$-labeled substrate pool is too rapid. Under these conditions it may be possible to derive reliable ATP and AN pool turnover data from habitats such as Krauss Pond simply by adding exogenous $\mathrm{PO}_{4}$ at concentrations sufficient to prolong the turnover time (i.e., uptake rate/starting concentration); however, it is unknown whether such $\mathbf{P}$ enrichments would affect the short-term turnover rates of either the $\alpha$-or $\gamma$-positioned P of ATP.

In the Algal Raceway experiment we terminated the ${ }^{32} \mathrm{P}$ uptake experiment prior to isotopic equilibrium (Figure 4). Nevertheless, both the $\alpha-\mathrm{P}$ and $\gamma$-P turnover times can still be estimated using a computer-assisted non-linear least-squares analysis of the specific activity versus incubation time data fit to equation (1). This statistical analysis yields ATP and AN pool turnover times of 23 and $64 \mathrm{~min}$, respectively, for the light incubation and a specific activity maximum (i.e., at isotopic equilibrium) of $150 \mathrm{nCi}^{32} \mathrm{P} \mu \mathrm{M}^{-1}$ ATP. Turnover times for the dark incubation were 15 and $80 \mathrm{~min}$ for the $\gamma-\mathrm{P}$ and $\alpha-\mathrm{P}$ of ATP, respectively, and a specific activity maximum of $113 \mathrm{nCi}^{32} \mathrm{P} \mu \mathrm{M}^{-1}$ ATP.

\section{Ecological interpretations of ATP labeling kinetics}

Energy flux calculations from $\gamma-P$ turnover. Since the adenine nucleotides constitute an energy-transducing system that stoichiometrically couples all metabolic processes, ATP flux (expressed as the amount of ATP hydrolyzed and subsequently regenerated from ADP) should be regarded as the ultimate metric for the measurement of total biochemical energy flux. Consequently, the measurement of $\gamma$-P ATP mass flux (i.e., turnover rate $X$ concentration) should be sufficient to directly compare and contrast biochemical energy fluxes among diverse microbial communities. However, if we wish to compare biochemical energy flux with other energy forms, such as radiant energy taken up by photosynthetically active organisms or microcalorimetrically determined biological heat production, we need to convert calories or joules into ATP flux, or vice versa. For ecological applications it might be appropriate to use the standard free energy of hydrolysis of ATP $\left(\Delta G_{A T P}^{0}\right)$ as the basis for energy conversion. At 'standard' conditions (i.e., 
Table I. Calculation of biochemical energy flux from ATP concentration and turnover rate data.

\begin{tabular}{|c|c|c|c|}
\hline Habitat & $\begin{array}{l}\text { ATP } \\
\text { pool } \\
\left(\text { nmol }^{-1}\right)\end{array}$ & $\begin{array}{l}\text { ATP turnover } \\
\text { (nmol } \gamma \text {-P } \\
\left.1^{-1} h^{-1}\right)\end{array}$ & $\begin{array}{l}\text { Energy flux } \\
\left(\mu \text { cal } 1^{-1} h^{-1}\right)\end{array}$ \\
\hline $\begin{array}{l}\text { Ocean Station } \\
\text { Algal Raceway }\end{array}$ & $0.05-010$ & $0.06-0.12$ & $1.4-2.8$ \\
\hline Light incubation & 145 & 380 & 8700 \\
\hline Dark incubation & 225 & 900 & 20600 \\
\hline
\end{tabular}

“Calculation assumes in vivo free energy of hydrolysis to be equivalent to $-23 \mathrm{kcal} \mathrm{mol}^{-1}$ ATP (1.e.. $\gamma+\beta$ ).

$\mathrm{pH} 7.0,25^{\circ} \mathrm{C}$, concentration of $1 \mathrm{M}$ for reactant and product) the hydrolysis of the $\gamma-\mathrm{P}$ and $\beta$-P each yields a value of $-7.3 \mathrm{kcal}^{-1} \mathrm{ATP}$ hydrolyzed to ADP, or ADP hydrolyzed to AMP. However, it is debatable whether this value represents the actual free energy of hydrolysis of ATP in intact cells, since intracellular conditions deviate considerably from standard conditions. Consequently, conversion of $\gamma$-P ATP turnover into calories can never be exact unless all implied conditions are known, a constraint which is virtually impossible to satisfy in samples of mixed populations. Nevertheless, it is likely that under physiological (intracellular conditions in natural living plankton) conditions there is a fairly uniform $\Delta \mathrm{G}_{\mathrm{ATP}}$ for most cells which does not deviate substantially from the $-11.5 \mathrm{kcal} \mathrm{mol}^{-1}$ measured by Wilson et al. (1974). Since the $\gamma-\mathrm{P}$ and $\beta$-P are expected to have equivalent turnover times, which is confirmed by our own direct measurements, and consequently equal energy fluxes, we have assumed a value of -23 kcal mol ${ }^{-1}$ ATP $(\gamma+\beta)$ hydrolyzed for our extrapolations (Table I). These data indicate that biochemical energy flux varies substantially among habitats but in a more or less predictable manner related to standing stocks of microbial cells. In the absence of any independent techniques which might be used to estimate biochemical energy flux, we cannot comment on the accuracy of our estimates.

Growth rate estimates from $\alpha-P$ tumover. ATP is a precursor for the biosynthesis of nucleic acids, histidine and of nucleotide co-factors such as NAD, FAD and coenzyme A (Chapman and Atkinson, 1977). RNA is the major sink, being responsible for approximately $75 \%$ of the $\alpha$-P flux through the ATP pool. Therefore it is reasonable to assume that $\alpha-\mathrm{P}$ turnover rates will be correlated with rate of RNA synthesis, and hence cell growth. Specific growth rates $(\mu)$ were calculated from the $\alpha$-P turnover data using the assumption that the total AN pool turns over 30-50 times per generation independent of growth rate (Chapman and Atkinson, 1977). There was an excellent correspondence between $\mu$ derived from $\alpha$-P turnover and independent measures of DNA synthesis and carbon production (Table II). This is encouraging for future ecological applications because the $\alpha$-P turnover method is relatively simple, inexpensive and highly sensitive.

Calculation of the pool size of total available $P$ in water samples. Rigler $(1956,1973)$ was the first to demonstrate that the conventional molybdenum method for orthophosphate determination in natural water samples may result in severe over-estimation, especially at low P concentrations, and that SRP may actually consist of a heterogeneous pool of P-containing compounds which are not all equally available for biological uptake. Since 
Table II. Comparison of specific growth rates $(\mu)$ estimated from independent measurements.

\begin{tabular}{llll}
\hline Habitat & \multicolumn{2}{l}{ Specific growth rate $\left(\mathrm{d}^{-1}\right)$} & \\
\cline { 2 - 4 } & $\begin{array}{l}\alpha \text {-P-ATP } \\
\text { numover } \\
\text { method }^{\mathrm{a}}\end{array}$ & $\begin{array}{l}\text { Carbon net } \\
\text { production } \\
\text { method }^{\mathrm{b}}\end{array}$ & $\begin{array}{l}\text { DNA } \\
\text { synthesis } \\
\text { method }^{\mathrm{c}}\end{array}$ \\
\hline $\begin{array}{l}\text { Algal Raceway I } \\
\text { Algal Raceway II }\end{array}$ & $0.16-0.33$ & 0.22 & $-\mathrm{d}$ \\
Ocean Station & $0.31-0.52$ & 0.33 & $-\mathrm{d}$ \\
& $0.41-0.70$ & $-\mathrm{d}$ & $0.15-0.45$ \\
\hline
\end{tabular}

aCalculation assumes that $\alpha-P$ turns over 30-50 times per generation.

bMeasured directly by daily sampling of particulate organic carbon and subsequent dilution of the cultures to maintain a steady population density.

cThe standing stock (cellular carbon) was calculated from ATP concentrations by assuming that ATP represents $0.4 \%$ of the total cellular carbon (i.e., C:ATP $=250: 1$ ). Production of cellular carbon was calculated from DNA synthesis, assuming a C:DNA ratio of 50:1.

dData not available.

Table III. Calculation of the pool size of extracellular available phosphorus (EAP).

\begin{tabular}{|c|c|c|c|c|}
\hline Habitat & $\begin{array}{l}\text { Measured SRP } \\
\text { concentration } \\
(\mu \mathrm{M})\end{array}$ & $\begin{array}{l}\text { Measured } \\
\text { sp. act. } \\
\text { of } \gamma-\mathrm{P} \\
\left(\mu \mathrm{Ci}^{32} \mathrm{P} \mu \mathrm{M}-1\right)\end{array}$ & 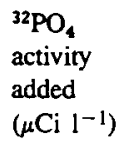 & $\begin{array}{l}\text { Calculated } \\
\text { EAP } \\
\text { concentration } \\
(\mu \mathrm{M})\end{array}$ \\
\hline $\begin{array}{l}\text { Ocean } \\
\text { Station }\end{array}$ & 0.13 & 1500 & 162 & $0 . \mathrm{il}_{1}$ \\
\hline $\begin{array}{l}\text { Algal } \\
\text { Raceway } !\end{array}$ & $>100$ & $2.9 \times 10^{-3}$ & 2000 & 6900 \\
\hline $\begin{array}{l}\text { Algal } \\
\text { Raceway II }\end{array}$ & $>100$ & 0.15 & 2000 & 133 \\
\hline Krauss Pond & 0.80 & 2730 & 966 & 0.35 \\
\hline
\end{tabular}

then, many investigators have struggled with this problem and it is still not easy to obtain reliable data on the concentration of the TDP pool (both inorganic and organic) utilized by micro-organisms in aquatic environments. $P$ uptake is usually measured by labeling a specific $\mathrm{P}$ pool with ${ }^{32} \mathrm{P}$ or ${ }^{33} \mathrm{P}$ and subsequent determination of the radioactivity incorporated into particulate matter. If the specific activity of the substrate pool is known, precise $\mathbf{P}$ uptake rates (or $\mathbf{P}$ fluxes if steady-state is assumed) can be calculated as mol $\mathrm{P}^{-1} \mathrm{~h}^{-1}$. If it is not possible to determine the specific activity of the extracellular substrate pool, as in the case of a homogeneous pool of unknown concentration, we can still measure absolute $P$ uptake rates if we reverse the approach by determining the specific radioactivity of the acceptor (intermediate) pool. For this application, certain ideal requirements should be satisfied, including: (1) the specific radioactivity of the precursor pool(s) and its (their) P-flux(es) into $\gamma$-P-ATP must be constant over the duration of the labeling period; (2) the acceptor pool must be furnished uniquely by extracellular sources; (3) the acceptor pool has to be an intermediate pool with a time constant input and output during the observed time interval; and (4) the turnover time of the acceptor pool must be at least five times shorter than the observed time interval of P-uptake measured so that isotopic equilibrium can be achieved. We believe that the ATP pool (specifically $\gamma$-P of ATP) can meet all of the requirements listed, with the possible exception of No. 2. 
In certain cases, however, we are able to set an upper limit to the contribution of $\mathbf{P}$ from an intracellular source(s), as discussed below. For the data summarized in Table III we assume that the isotopic equilibrium reached in the $\gamma$-P position of ATP accurately reflects the specific radioactivity of the extracellular available TDP pool.

At Ocean Station the pool size of available TDP is nearly identical to the measured SRP pool, suggesting that orthophosphate is the primary extracellular phosphorus source and that there is undetectable isotope dilution occurring in the intracellular environment. However, we must emphasize that alternate interpretations are also possible (for example, 'unavailable' SRP fraction is exactly balanced by 'non-SRP' sources). In Krauss Pond the available P pool appears to be considerably smaller than the measured SRP pool. These findings are in accordance with results discussed first by Rigler (1966) and subsequently by others (Chamberlain and Shapiro, 1969).

In summary, we have described the relative merits and general ecological application of a new method which measures the turnover of ATP and total adenine nucleotide pool in naturally occurring microbial communities. Our preliminary results suggest that this method may be used to study microbial growth rate, biochemical energy flux, carbon production and P-dynamics. Although the data presented herein must be considered preliminary, we feel that this method will eventually provide a meaningful approach for testing hypotheses regarding the control of microbial growth and nutrient cycling in aquatic ecosystems.

\section{Acknowledgements}

We wish to thank G.Taylor and M.Pace for comments and criticism, U.Magaard and D.Burns for expert technical assistance and L. Wong for typing numerous drafts of this manuscript. E.Laws and S. Taguchi provided us with data from the algal mass culture facility in Honolulu (Algal Raceway). The first author expresses his appreciation to the Department of Oceanography, University of Hawaii, and especially to D.M.Karl, for making this collaboration possible and to the Swiss Federal Institute for Water Resources and Water Pollution Control (EAWAG/ETH) for financial support. This research was supported in part by NSF grant OCE82-16673, awarded to D.M.Karl.

\section{References}

Atkinson,D.E. (1977), Cellular Energy Metabolism and its Regulation, published by Academic Press, New York. Berman,T. and Skyring,G.W. (1979), Phosphorus cycling in aquatic microorganisms studied by phased uptake of ${ }^{33} \mathrm{P}$ and ${ }^{32} \mathrm{P}$, Curr. Microbiol., 2, 47-49.

Chapman,A.G. and Atkinson,D.E. (1977), Adenine nucleotide concentrations and turnover rates. Their correlation with biological activity in bacteria and yeast, Adv. Microbiol. Physiol., 15, 253-306.

Chamberlain, W. and Shapiro,J. (1969), On the biological significance of phosphate analysis: comparison of standard and new methods with a bioassay, Limnol. Oceanogr., 14, 921-927.

Cosgrove,D.J. (1977), Microbial transformations, in the phosphorus cycle, in Alexander,M. (ed.), Advances in Microbial Ecology, Vol 1, Plenum Press, New York, pp. 95-134.

Fenchel,T. and Blackburn,T.H. (1979), Bacteria and Mineral Cycling, published by Academic Press, London.

Halmann,M. and Stiller,M. (1974), Tumover and uptake of dissolved phosphate in freshwater, a study in Lake Kinneret, Limnol. Oceanogr., 19, 774-783.

Hodson, R.E., Holm-Hansen,O. and Azam, F. (1976), Improved methodology for ATP determination in marine environments, Mar. Biol., 34, 143-149.

Kanai,R. and Simonis,W. (1968), Einbau von ${ }^{32} \mathrm{P}$ in verschiedene Phosphatfraktionen, besonders Polyphosphate, bei einzelligen Gruenalgen (Ankistrodesmus braunii) im Licht und im Dunkeln, Arch. Mikrobiol.; 62, 56-71. 
Karl,D.M. (1981), Simultaneous rates of ribonucleic acid and deoxyribonucleic acid synthesis for estimating growth and cell division of aquatic microbial communities, Appl. Environ. Microbiol., 42, 802-810.

Karl,D.M. and Bossard,P. (1985a), Measurement and significance of ATP and adenine mucleotide pool turnover in microbial cells and environmental samples, J. Microbiol. Methods, 3, 125-139.

Karl,D.M. and Bossard,P. (1985b), Measurement of microbial nucleic acid synthesis and specific growth rate by ${ }^{32} \mathrm{PO}_{4}$ and $\left[{ }^{3} \mathrm{H}\right]$ adenine: field comparison, Appl. Environ. Microbiol., 50, 706-709.

Karl,D.M., Winn,C.D. and Wong,D.C.L. (1981), RNA synthesis as a measure of microbial growth in aquatic environments: I. Evaluation, verification and optimization of methods, Mar. Biol., 64, 1-12.

Laws,E.A., Redalje,D.G., Haas,L.W., Bienfang,P.K., Eppley,R.W., Harrison,W.G., Karl,D.M. and Marra,J. (1984), High phytoplankton growth and production rates in oligotrophic Hawaiian coastal waters, Limnol. Oceanogr., 29, 1161-1169.

Lean,D.R.S. (1973), Movements of phosphorus between its biologically important forms in lakewater, J. Fish. Res. Board Can., 30, 1525-1536.

Lean,D.R.S. and White,E. (1983), Chemical and radiotracer measurements of phosphorus uptake by lake plankton, Can. J. Fish. Aquat. Sci., 40, 147-155.

Lehman,J.T. (1980), Cycling of P among phytoplankton, herbivorous zooplankton, and the lake water, in Scavia,D., and Moll,R., (eds.) Special Report No. 83 of the Great Lakes Research Division, University of Michigan, MI.

Medveczky,N. and Rosenberg,H. (1971), Phosphate transport in Escherichia coli, Biochum. Biophys. Acta, 241, 494-506.

Miyachi,S. and Tamiya,H. (1961), Distribution and turnover of phosphate compounds in growing Chlorella cells, Plant Cell Physiol., 2, 405-414.

Nalewajko,C. and Lean,D.R.S. (1981) Phosphorus, in Morris,I. (ed.), Studies in Ecology, Vol. 7, Blackwell Scientific, Oxford, pp. 235-258.

Perry,M.J. (1976), Phosphate utilization by an oceanic diatom in phosphorus-limited chemostat culture and in the oligotrophic waters of the central North Pacific, Limnol. Oceanogr., 21, 88-107.

Rhee,G.-Y. (1973), A continuous culture study of phosphate uptake, growth rate and polyphosphate in Scenedesmus sp., J. Phycol., 9, 495-506.

Rigler,F.H. (1956), A tracer study of the phosphorus cycle in lake water, Ecology, 37, 550-562.

Rigler,F.H. (1966), Radiobiological analysis of inorganic phosphorus in lakewater, Verh. Int. Verein. Limnol., 16, 465-470.

Rigler,F.H. (1973), A dynamic view of the phosphorus cycle in lakes, in Griffith,E.J. et al., (eds.) Environmental Phosphorus Handbook, pp. 539-572, Wiley-Interscience, New York.

Scavia,D. (1980), Conceptual model of phosphorus cycling, in Scavia,D., and Moll,R. (eds.), Special Report No. 83 of the Great Lakes Research Division, University of Michigan, MI, pp. 119-140.

Taft,J.L., Loftus,M.E. and Taylor,W.R. (1977), Phosphate uptake from phosphomonoesters by phytoplankton in the Chesapeake Bay, Limnol. Oceanogr., 22, 1012-1021.

Tarapchak,S.J., Slavens,D.R. and Maloney,L.M. (1981), Abiotic versus biotic uptake of radiophosphorus in lake water, Can. J. Fish. Aquat. Sci., 38, 889-895.

Vogler,P. (1965), Beiträge zur Phosphatanalytik in der Limnologie, Fortschr. Wasserchem. Grenzgeb., 2, 109-119.

Watt,W.D., and Hayes,F.R. (1963), Tracer study of the phosphorus cycle in sea water, Limnol. Oceanogr., 8, 276-285.

Wilson,D.F., Stubbs,M., Veech,R.L., Erecinska,M. and Krebs,H.A. (1974), Equilibrium relations between the oxidation-reduction reactions and the adenosine triphosphate synthesis in suspensions of isolated liver cells, Biochem. J., 140, 57-64.

Received May 1984; accepted October 1985 